\title{
Virtual lead user communities: Drivers of knowledge creation for innovation
}

Citation for published version (APA):

Mahr, F. D., \& Lievens, A. (2012). Virtual lead user communities: Drivers of knowledge creation for innovation. Research Policy, 41(1), 167-177. https://doi.org/10.1016/j.respol.2011.08.006

Document status and date:

Published: 01/01/2012

DOI:

10.1016/j.respol.2011.08.006

Document Version:

Publisher's PDF, also known as Version of record

Document license:

Taverne

Please check the document version of this publication:

- A submitted manuscript is the version of the article upon submission and before peer-review. There can be important differences between the submitted version and the official published version of record.

People interested in the research are advised to contact the author for the final version of the publication, or visit the DOI to the publisher's website.

- The final author version and the galley proof are versions of the publication after peer review.

- The final published version features the final layout of the paper including the volume, issue and page numbers.

Link to publication

\footnotetext{
General rights rights.

- You may freely distribute the URL identifying the publication in the public portal. please follow below link for the End User Agreement:

www.umlib.nl/taverne-license

Take down policy

If you believe that this document breaches copyright please contact us at:

repository@maastrichtuniversity.nl

providing details and we will investigate your claim.
}

Copyright and moral rights for the publications made accessible in the public portal are retained by the authors and/or other copyright owners and it is a condition of accessing publications that users recognise and abide by the legal requirements associated with these

- Users may download and print one copy of any publication from the public portal for the purpose of private study or research.

- You may not further distribute the material or use it for any profit-making activity or commercial gain

If the publication is distributed under the terms of Article $25 \mathrm{fa}$ of the Dutch Copyright Act, indicated by the "Taverne" license above, 


\title{
Virtual lead user communities: Drivers of knowledge creation for innovation
}

\author{
Dominik Mahr $^{\mathrm{a}, *}$, Annouk Lievens ${ }^{\mathrm{b}}$ \\ a Maastricht University, Department of Marketing and Supply Chain Management, PO Box 616, NL-6200 MD Maastricht, The Netherlands \\ ${ }^{\mathrm{b}}$ University of Antwerp, Marketing Department, BE-2000 Antwerpen, Belgium
}

\section{A R T I C L E I N F O}

\section{Article history:}

Received 1 March 2010

Received in revised form 1 July 2011

Accepted 15 August 2011

Available online 10 September 2011

\section{Keywords:}

Lead users

Virtual communities

Knowledge value

Innovation

\begin{abstract}
A B S T R A C T
This study examines the creation of innovation-related knowledge in virtual communities visited mainly by lead users. Such communities enable firms to access a large number of lead users in a cost-efficient way. A propositional framework relates lead users' characteristics to unique virtual community features to examine their potential impact on the development of valuable innovation knowledge. The authors empirically validate this framework by analyzing online contributions of lead users for mobile service innovation projects. The findings indicate that the value of their contributions stems from their ability to suggest solutions instead of simply describing problems or stating customer needs. Lead users' technical expertise also makes them particularly well-suited to develop new functionalities, but less so for design and usability improvements. The digital context favors the creation of explicit knowledge that can be easily integrated into the development of new products. Finally, contributions given by lead users in a proactive way contain more novel insights than reactive contributions such as answers to community members' questions. The findings should help managers stimulate, identify, and improve the use of lead users' input in virtual communities.
\end{abstract}

(C) 2011 Elsevier B.V. All rights reserved.

\section{Introduction}

Firms such as Microsoft, IBM, BMW, and Nokia increasingly invest in virtual communities to solicit user contributions during their innovation processes (IBM, 2008); our analysis of the hightech firms listed in the S\&P 500 index indicate that more than $80 \%$ have established virtual user communities to benefit from users' input. This trend represents a shift from a closed, internal R\&D process toward an open collaboration that may provide more novel and diverse insights into customers' needs and problem-solving abilities (Chesbrough, 2003; von Hippel, 2005). A firm's competence to identify and integrate knowledgeable users into the development of new products and services offers a primary source of competitive advantage (Prahalad and Ramaswamy, 2004). Hence, it is crucial for firms to understand how virtual user communities function and obtain insight into the nature of the knowledge they might provide for the innovation process.

In general, the impact of customers' input to new products and services remains highly disputed. On the one hand, customers may not be able to provide new insights because of their limited imagination about products or services that do not yet exist (Davis, 1993). In this case customer input would not lead to more successful

\footnotetext{
* Corresponding author. Tel.: +31 4338 83855; fax: +31 433884918 .

E-mail addresses: d.mahr@maastrichtuniversity.nl (D. Mahr), annouk.lievens@ua.ac.be (A. Lievens).
}

offerings (Henard and Szymanski, 2001). In fast developing markets such as the high-tech industry in particular, listening too closely to customers may hinder the development of radically new offers (Christensen and Bower, 1996). On the other hand, customers represent a unique source of knowledge, critical for the success of new products and services, that cannot be obtained from other sources (Prahalad and Ramaswamy, 2004). From this perspective, customers, as future buyers, are best suited to provide innovating firms with information about their needs (Jaworski and Kohli, 1993). In this case customer involvement should lead to new product ideas that are more novel, valued by customers, and easily implementable (Kristensson et al., 2004).

Some research has tried to reconcile these contradictory arguments by suggesting that the impact of customers' involvement depends on the type of customers. Specifically, lead user theory holds that the involvement of leading-edge customers, who are ahead of market trends and expect significant benefits from innovations, produce commercially more successful products (Morrison et al., 2004; von Hippel, 2005). Typically, lead users possess great expertise and usage experience, and they exhibit personality traits such as a high locus of control and strong innovativeness (Ozer, 2009; Schreier and Pruegl, 2008). These characteristics enable lead users, in contrast with non-lead users, to provide accurate information about their needs and problems and to develop solutions to those needs (von Hippel, 2005).

Prior research on lead users closely examines their nature (Morrison et al., 2004), the implementation of lead user-driven 
innovation processes in firms (Olson and Bakke, 2001), and their impact on successful innovation (Lilien et al., 2002; for a review, see Luethje and Herstatt, 2004). However, recent research also indicates that lead users might not be an appropriate source of some types of knowledge (Magnusson, 2009), because these tech-savvy consumers possess a level of technical expertise and problemsolving persistence that ordinary users do not reach. In summary, extant research lacks a deep understanding of the specific type of knowledge created by lead users.

Moreover, research on lead users largely ignores the potential influence of virtual communities. Although some virtual communities focus specifically on lead user-driven innovation, their demarcations from other popular digital communities, such as product support or open source communities, have not been well established. Especially, the role of the hosting firm and the impact of community features on lead users' contributions have received limited attention (Nambisan, 2002; von Hippel, 2007), even though such information would provide important foundations for further research and recommendations for innovation management (Hoyer et al., 2010). Moreover, empirical research on lead user contributions has focused on communication channels such as face-to-face workshops (Kristensson et al., 2004) or specific electronic tools (Piller and Walcher, 2006). Despite calls for more research into new and less costly ways to obtain knowledge from lead users (Hoyer et al., 2010; Luethje and Herstatt, 2004), empirical research that investigates the value of lead users' contributions through the most common digital communication channel, namely, discussion forums on virtual communities, remains scant.

This study addresses these research gaps by examining the creation of innovation-related knowledge in virtual lead user communities (VLUC) to answer two main research questions: (1) What defines a virtual lead user community, and what features distinguish it from other communities? (2) What drives the creation of valuable knowledge through lead user contributions? We address these questions by first reviewing previous studies on lead users and knowledge creation in digital networks and thereby establishing a definition of VLUCs. On the basis of our review, we develop a propositional framework of lead users' contributions in virtual communities. Hereby we relate established characteristics of lead users to the communities' features and hypothesize their impact on the development of novel and relevant knowledge. We empirically test this framework and discuss the results, before we conclude by formulating managerial implications for innovating firms. Our findings should help companies design and manage VLUCs, as well as identify and exploit lead users' input during their innovation process.

\section{Conceptual background}

The creation of new knowledge is the central activity during the development of new products and services (Madhavan and Grover, 1998). Firms adopt processes to acquire, disseminate, and interpret new information and learn about their customers' needs and preferences (Jaworski and Kohli, 1993). They frequently build enduring relationships with customers - the buyers of their current and future products - to obtain such information. The interaction with customers across different stages of the innovation project improves the speed and effectiveness of the new product development process (Carbonell et al., 2009) and the success of resultant new products (Gruner and Homburg, 2000).

Because customers cannot always imagine and express their needs, firms must develop a proactive approach to learn about latent needs (Narver et al., 2004). Such needs emerge slowly and enter people's consciousness only when users experience various situations and encounter difficulties during their daily tasks (Kristensson et al., 2008). Especially in turbulent market environments with nonlinear and unpredictable changes, formal, longwinded processes to understand customers' preferences become too inflexible and slow to adapt (Eisenhardt and Martin, 2000). Customers' needs are often unclear in the beginning of the development process and change continuously, which makes it impossible to establish them conclusively. Instead of formal and detailed analytical processes, firms require simple and experiential routines that can create new knowledge about any specific situation (Eisenhardt and Martin, 2000).

Furthermore, customers tend to form their preferences when they experience difficulties and must make decisions (Bettman et al., 1998). As they engage in experiential learning, or 'learning by doing', to resolve their issue (Arrow, 1962), these customers explore problems in real-life settings and develop solutions in a trial-and-error manner. These iterations repeat until the customer finds an acceptable fit between his or her need and a solution (von Hippel, 1994). This learning approach thus reflects the evolutionary, dynamic nature of knowledge (Zollo and Winter, 2002).

Conceptually, the process closely matches Senge's (1990) wheel of learning, in which people set decision parameters and make decisions ('decide'), carry out the activity ('do'), analyze the outcome ('reflect'), and then think of new ideas and possibilities for action ('connect'). Critical to such 'learning by doing' are short and continuous iteration cycles for building and running new prototypes, analyzing test results, and then designing new prototypes. Customers experiment with the prototypes, respond with assessments of their use experiences and develop ideas for improvements (Thomke, 2001). This customer integration approach, sometimes called 'rapid prototyping', is particularly popular in software industries. It facilitates the exchange of need-related information that resides in customers and solution-related information possessed by the innovating firm (Nambisan, 2002; von Hippel, 2005) and produces more useful knowledge and better matches with customer requirements than non-iterative methods (von Hippel, 1994).

Such knowledge creation can also be amplified if the firm includes more and carefully selected customers. As we noted previously, customers with lead user characteristics contribute to commercially successful products (Morrison et al., 2004; von Hippel, 2005), though they also might hinder the creation of some types of knowledge because of their differences from ordinary users (Magnusson, 2009; Moore, 2002). Furthermore, virtual communities, by blurring geographic boundaries, facilitate access to a more diverse set of customers at a low cost (Hoffman and Novak, 1996). Knowledge creation benefits from social interactions among community members. That is, new ideas may come from individual customers, but the interactions among these individuals enable them to build on one another's knowledge and experiences, which plays a critical role in developing ideas (Rowley et al., 2007). However, the computer-mediated nature of virtual communities and the limited capacity they offer to transfer physical and social cues, compared with face-to-face meetings, may affect the knowledge creation they produce (Sproull and Kiesler, 1986). Thus, taking into account both the advantages and the constraints associated with lead users in digital communities, we examine the types of knowledge created in VLUCs.

\subsection{Lead user characteristics}

Studies on customer involvement in successful innovations demonstrate the importance of lead users (von Hippel, 2005), who contribute the majority of product improvements (Franke and Shah, 2003) and develop products that are ready for the market (Luethje, 2004). Prior lead user studies investigate their nature and identify lead users according to their (1) traits, (2) knowledge, and (3) status (Luethje and Herstatt, 2004; Schreier and Pruegl, 2008). 
We build on this research to explore how such characteristics might influence the creation of innovation-related knowledge.

\subsubsection{Traits}

Literature on creative problem solving and personality types associates both locus of control and innovativeness with the rapid and expansive adoption of new products (Schreier and Pruegl, 2008). Locus of control refers to an inner belief that outcomes primarily depend on people's own actions. Product users with a high internal locus of control are more willing to undertake new usage experiences, challenge their existing routines, and commit themselves to new situations. They pursue difficult tasks and invest more in mastering them than do non-lead users (Schreier and Pruegl, 2008). Innovativeness refers to an openness toward innovation and its early adoption (Im et al., 2003). Innovative personalities are more willing to change their behavior, search for novel products, and cope with uncertain situations at the leading edge of the market. In aggregate, lead users 'live in the future' (Luethje, 2004), in the sense that they detect opportunities for improvement ahead of others and address them through self-developed solutions.

\subsubsection{Knowledge}

In addition to variables related to their general personality, product-specific parameters can describe lead users. They possess great product knowledge stemming from two sources. First, usage experience results from the frequent use and consumption of products. Such learning by doing leads to vivid, applicable, and credible knowledge (Schreier and Pruegl, 2008). Second, product environment-related knowledge stems from various sources, beyond product usage, such as general know-how about the product's structural design, technologies used in existing products, or general market trends. A high level of technical knowledge enables lead users to detect their own needs and translate them into specifications understood by developers (Luethje, 2004). Combining the product knowledge of lead users with other types of knowledge triggers creative processes (Cohen and Levinthal, 1990). Prior research therefore has demonstrated that higher levels of productrelated expertise relate positively to the likelihood for innovation and lower development costs compared with innovation that relies on less informed users (Luethje, 2004; Ozer, 2009).

\subsubsection{Status}

Empirical research related to user innovation suggests that lead users are ahead of non-lead users with regard to important trends in their markets (Morrison et al., 2004), so they experience product needs significantly earlier than do many others in that market (von Hippel, 1986). If these lead users develop solutions for their own needs, the solutions might also be suitable for future problems in the mass market. For example, mountain bike enthusiasts of an outdoor community developed a new disc brake design for mountain bikes that is now commercialized and offered to regular bikers (Luethje, 2004). The anticipated benefits of the solution determines the level of commitment and resources that a lead user is willing to invest (Lengnick-Hall, 1996); high levels of expected returns motivate lead users to engage actively in innovation partnerships with firms and even take over entire innovation tasks (Luethje, 2004; Schreier and Pruegl, 2008). Particularly in end-consumer markets, intrinsic motivations, such as satisfaction achieved by solving the problem or entertainment, are also important reasons for engagement (Franke and Shah, 2003). In summary, anticipated personal gains motivate lead users to be actively involved in sharing creative ideas and providing feedback about new products.

\subsection{Virtual lead user communities}

\subsubsection{User innovation communities}

New product developments with customers rarely happen individually but rather require interactions among like-minded customers who talk about their usage experiences, raise questions, present solutions, offer answers, and laugh at mistakes (Fueller and Matzler, 2007; Rowley et al., 2007). Within the community, customers freely reveal knowledge that encourages others to build on it, as well as reflect on their own experiences. Even if hosting firms set the ground rules for participating, knowledge is created by independent members, who consider the community to be the owner of that knowledge (Sawhney and Prandelli, 2000). When firms provide the community with a new product, members test it in their own environment. They discuss the test results and reach a shared understanding of the product's weaknesses and strengths. The innovating firm learns from the community's interaction and may rethink its initial ideas and develop a new product that addresses newly detected requirements and problems (Fueller and Matzler, 2007). A series of experiments and trial-and-error runs can generate alternative, improved product designs that are closer to the commercially viable version. The users interact in communities and develop collective knowledge that is accessible to every user and firm employee. In contrast, in traditional innovation processes inside firms, knowledge typically can be accessed only through firms' new product development teams (Franke and Shah, 2003).

Furthermore, the increase in digitalization and decrease in the costs of communication have led to the exponential growth of user innovation platforms. Companies across many industries, including automotive (e.g., BMW M Power community), retailing (e.g., My Starbucks Idea), health care (e.g., Mayo Clinic Social Media and Blog for Innovation), and high-tech (Dell IdeaStorm), engage with customers to obtain valuable knowledge for their innovations. The creation of valuable knowledge depends on the quantity and quality of the interaction, such that three main conditions enable communities to flourish. First, customers must have incentives to innovate and communicate about these innovations within the community. Despite their considerable engagement and time investments, customers typically do not receive a financial payment, but expect a considerable return for their participation in other forms (Harhoff et al., 2003). Both extrinsic motives, such as peer recognition, and intrinsic motives, such as fun, curiosity, or support for others, can play roles. Hosting firms should balance these motives carefully though, because a shift might negatively affect customer participation. For example, adding a financial reward may decrease interaction intensity and creativity (Franke and Shah, 2003). A second condition for flourishing community suggests that customers' needs are heterogeneous, so information about them is dispersed widely among users. These needs cannot be served or satisfied if only few community members contribute; rather, many contributing customers must be willing to invest their resources and search for various ways to match their needs (von Hippel, 2005). Third, user-developed innovations, and more specifically the communication surrounding these innovations, must be transferable through digital channels. Explicit knowledge, embodied in unambiguous data, facts and figures, or instructions is easily transferable. Tacit knowledge also can be transmitted in virtual communities through descriptions of usage experiences, shared reflections, or tool kits (Fueller and Matzler, 2007). To produce various types of knowledge, firms should break down the innovation task into modular subtasks to which users can contribute separately. This method reduces users' necessary time investments and cognitive efforts. The innovating firm then obtains information about each subtask through several iterations and reassembles the overall innovation task itself (von Hippel, 1994). 


\subsubsection{Definition of VLUC}

We define a VLUC as a firm-hosted virtual community in which members with lead user characteristics interact to create knowledge about new products and services. The innovating firm and community members communicate in short iteration cycles and enhance collective knowledge about users' needs and potential solutions. An open-minded and future-oriented culture and an incentive system help enforce the development of solutions for specific innovations.

\subsubsection{Key features of VLUCS}

In turn, VLUCs consist of several features that distinguish them from other communities, such as open source (Bagozzi and Dholakia, 2006), user support (Dholakia et al., 2009), or brand (Muniz and O'Guinn, 2001) communities. VLUCs complement these communities, rather than replacing them, because VLUCs possess distinct objectives, audiences, participation motives, and design features. These features determine the extent of creative and meaningful knowledge that the community can develop (Amabile et al., 1996). Exemplary features relate to the nature of lead users, including their (1) general traits, (2) knowledge, and (3) status in the market, as well as (4) the nature of the digital channel.

First, a VLUC's culture tolerates errors and diversity, so it encourages the future-oriented, innovative lead users to share their original views and outside-the-box thinking (Joshi and Sharma, 2004). The trial-and-error tools available in VLUCs support experimental activities during innovation processes (Thomke, 2001). Unlike an offline setting, in which the firm must select lead users through a labor-intensive screening process (von Hippel, 1986), VLUCs are typically unrestricted in terms of access, so firms cannot preselect users. The ground rules for participation enforce the innovative culture and thus represent a key element to ensure the participation of likeminded people. This is also supported by an unambiguous positioning of the VLUC and a clear communication of its purpose (e.g., on the 'About us' or 'rules of participation' pages). If necessary, the hosting firm should direct users with unrelated posts, such as assistance requests, to other communities. However, in some cases, the VLUC host restricts access to the community and requires members to qualify as innovators. Such 'gated' communities allow for better preselection of members, but their associated privacy concerns and inconvenience might discourage participation by some lead users (Shah, 2006).

Second, a VLUC encourages lead users to update their knowledge by providing, for example, simple and clear navigation through prior entries, semantic knowledge maps with pointers to sources, 'tag clouds' that depict the most popular content, and advanced search functionalities to encourage knowledge creation (Antioco et al., 2008). Access to databases containing product-related information and user manuals should enhance lead users' product understanding (Zahay et al., 2011). Firms can offer opportunities for making new usage experiences through iterative prototype testing which in turn should foster knowledge sharing (Thomke, 2001).

Third, VLUCs stimulate contributions by appealing to lead users' intrinsic and extrinsic motives. Firms might design reward systems that reflect a contributor's innovation performance in the form of explicit rewards (e.g., innovator of the month), rankings (e.g., 'Top 10 most viewed comments'), or idea competitions (Piller and Walcher, 2006). They also should grant direct access to the development teams, such that staff provides personalized feedback to users. The resultant feeling of reciprocity and exclusiveness enhance users' self-esteem and satisfy their status-seeking needs (Nambisan, 2002). In contrast, in open source communities uncontrolled by companies, the intrinsic motivation is mainly enjoyment or altruism (Lakhani and Wolf, 2003). Furthermore, lead users develop reputations and identities within the community through the self-presentation functionalities the community offers. Members recognize peers' performance by tracking contribution histories and rating their contributions. For example, at threadless.com, community members vote on their peers' submitted t-shirt designs and elect a monthly 'Bestee' winner (Hoyer et al., 2010). Unlike communities that focus on social relationships among the members, the self-presentation profile in VLUCs remains often limited; users generally provide a nickname but reveal only limited personal data. This avoids bias in their assessments of their contributions and allows users to be more risky and creative as their identities are not revealed. In summary, various features trigger lead users' willingness to provide new insights or answers to questions in communities.

Fourth, digital channels favor explicit knowledge, such as facts and figures and clear status reports, but implicit knowledge rooted in stories and usage experiences can also be communicated (Roberts, 2000). Therefore, VLUCs use a wide range of functions to generate knowledge, ranging from simple contribution assessments (e.g., 'Promote' or 'Demote') to sophisticated trial-and-error tools. For example, in BMW's Customer Innovation Lab, virtual users can design and test a car's navigation and audio systems. Contribution opportunities also differ in their complexity and the challenges they offer users, such that they can address heterogeneous members' preferences and skills (Nambisan, 2002). Altogether, varied, seamlessly linked contribution tools aim to provide a compelling online or 'flow' experience (Hoffman and Novak, 1996), in which members are deeply involved in, remain intrinsically motivated by, and actively participate in the VLUC.

\section{Hypothesis development: Knowledge creation in VLUCs}

New product development, at its core, is a problem-solving process that requires information about customer problems and original and useful ideas to solve them (von Hippel, 2005). Research has demonstrated that the development of creativity and meaningful knowledge precedes new product success (Im and Workman, 2004) and that lead users possess the skills and knowledge to contribute to this knowledge. Typically, lead users analyze problems and produce solutions through iterative learning by doing (Luethje, 2004). Firms encourage this problem-solving approach by designing VLUCs that tap into the globally distributed knowledge and skills of their lead users and reinforce their motivation to contribute. This shift toward knowledge creation in digital networks means that customers connect with both other customers and the hosting firm (Sawhney and Prandelli, 2000).

In this study, we adopt the perspective of the hosting firm, whose ultimate objective is to extract knowledge that is novel and relevant for its innovation tasks (Im and Workman, 2004; Kristensson et al., 2004). Novel knowledge provides new insights and original ideas that serve as an inspiration for the hosting firm and broaden its knowledge base. Diverse knowledge and unique ideas originate in explorative activities such as experimentation and play (March, 1991) and constitute essential components for the successful development of new products and services (Amabile et al., 1996; Cohen and Levinthal, 1990). Relevant knowledge pertains to knowledge that matches the tasks at hand-in our study, a particular innovation project. Such knowledge may be the outcome of exploitation, such as the selection and refinement of products (March, 1991). Relevance increases if lead users provide meaningful and comprehensible information that can be integrated easily into the innovation tasks performed by the project team (Im and Workman, 2004; Kristensson et al., 2004). Both novelty and relevance determine the value of knowledge; a novel idea might be meaningless for a particular innovating firm, but a relevant idea might not be sufficiently original. Therefore, in line with prior creativity and innovation management studies (Amabile et al., 1996; 
Audia and Goncalo, 2007; Im and Workman, 2004; Magnusson, 2009; Oldham and Cummings, 1996), our dependent variable, the knowledge value of an individual VLUC contribution, is composed of two dimensions: novelty (i.e., uniqueness and originality of the contribution) and relevance (i.e., meaningfulness and appropriateness of the contribution for a specific innovation).

\subsection{Focus of lead users' contributions}

Successful innovation processes require two types of information: about users' needs in the experience context and about the solution that can address those needs (von Hippel, 2005). In VLUCs, customers can contribute to both types. They report their experiences by focusing either on the problems they encountered or on the solutions that could be developed to overcome these problems.

Because of their innovative, future-oriented character, lead users can not only detect problems but also look for and propose solutions (Luethje, 2004; Schreier and Pruegl, 2008). User's innovativeness supports seeking for novel information and products, solving complex problems, and experimenting with new ideas, which fuels the development of creative solutions (Im et al., 2003). Lead users recombine need-related information with insights from other fields and experiment until they accomplish a novel solution addressing these needs (von Hippel, 2005). Such a solutionfocused input matches the developer's tasks at hand because it can be immediately integrated into new product developments (Magnusson, 2009; van Aken, 2004). In contrast, problem-focused contributions must be understood and interpreted before the innovating firm can integrate the knowledge into new solutions. This process is prone to errors, because employees may misunderstand the user's contribution. Therefore, we hypothesize:

$\mathbf{H 1}$ (:). The knowledge value of contributions differs across the levels of focus. Solution-focused contributions provide greater value than do problem-focused contributions.

\subsection{Content of lead users' contributions}

In digital communities, customers take different roles during the innovation process and contribute varying content. For example, they might develop new design concepts or report technical breakdowns during prototype testing (Nambisan, 2002). Diverse and meaningful knowledge that includes a wide variety of content is critical for new product success (Cohen and Levinthal, 1990; Zahay et al., 2011). Studies investigating the impact of different content types on innovation success suggest four categories: performance/reliability, design/aesthetical appearance, usability/ergonomics, and functionality (Antioco et al., 2008; Krishnan and Ulrich, 2001). Their extensive use experience enables lead users to develop new functionalities that are practical and applicable in a real life setting (Schreier and Pruegl, 2008). Their strong technical expertise makes lead users also well suited to contribute original, creative ideas to new functionalities. Lead users can leverage on expertise that reaches considerably beyond specific products and markets and imaginatively apply it to new use contexts (Morrison et al., 2000).

However, they might be less well suited to suggest improvements for usability concerns, because they develop their own ways to use a product and overcome potential problems. Moreover, their focus on technical, as opposed to aesthetic, issues makes lead users less able to provide ideas about the appearance or design of a new product (Moore, 2002). Furthermore, lead users may report performance-related problems, such as breakdowns or slow execution, but the solutions to such problems require an in-depth understanding of the inside of a new offering. Because firms typically do not release complete information about newly developed products, for confidentiality reasons (Chesbrough, 2003), lead users have limited information about the product's inner architecture and operations. Consequently, lead users' solutions to performance issues tend to be of little value for product development.

We thus hypothesize:

$\mathbf{H 2}$ (:). The knowledge value of contributions differs across content types. Contributions related to functionality are of greater value than contributions related to design, usability, and performance.

\subsection{Initiation of lead users' contributions}

Contributions to the innovation process can either be selfinitiated and unrelated to prior contributions or in response to certain questions and building on prior contributions. The former type represents a proactive behavior that captures latent needs, whereas the latter entails responsive activities focused on expressed needs (Narver et al., 2004). Proactiveness is associated with more diverse, new, and more difficult-to-imitate knowledge (Atuahene-Gima et al., 2005) and is therefore more valuable for developing new, distinctive products.

Responses to prior comments may benefit user support communities, because they answer the questions of other users. Members may offer such answers for altruistic reasons, because they anticipate reciprocity, or to strengthen their group belonging (Nambisan and Baron, 2009). In innovation-oriented communities designed to develop novel knowledge, members' engagement is often triggered by being the first to solve a challenge or recognition as an 'innovator'. Self-initiated contributions better enrich the knowledge base with their diversity and unforeseen insights, which might even challenge existing knowledge (Atuahene-Gima et al., 2005). We hypothesize:

H3 (:). The knowledge value of contributions differs across levels of initiation. Self-initiated contributions provide greater value than do responding contributions.

\subsection{Codification of lead users' contributions}

Knowledge can be coded in different forms. It might contain facts and figures, clear requirements, status reports, and unambiguous statistics (i.e., explicit knowledge) or involve stories, usage experiences, analogies, and verbal images (i.e., implicit knowledge). This distinction represents a key dimension of knowledge tacitness (Polanyi, 1966). In addition to being implicit, tacit knowledge is also described as individual (versus general), embedded in intangible procedures (versus tangible artifacts and symbols), and informal (versus formal); it mainly gets transferred through interpersonal communication (Fueller and Matzler, 2007; Hansen, 1999; Roberts, 2000). Its complexity poses difficulties for transfers, but tacit knowledge is difficult for competitors to imitate, which makes it valuable for the innovation process (Nonaka, 1994). However, both forms of knowledge may be important and contain novel and relevant insights. Implicit knowledge includes product usage experiences that contain information about customers' latent needs and unexpressed motives (Madhavan and Grover, 1998). In contrast, explicit knowledge is less ambiguous, can be disseminated more quickly, and is easier to integrate into the development of new products than is tacit knowledge. Overall, the value of implicit and explicit knowledge essentially stems from different sources: implicit knowledge is more difficult for competitors to replicate, while explicit knowledge is less ambiguous.

Although early research on media channels has stated that knowledge transferred by digital channels is always explicit, because it is in a written form (Daft and Lengel, 1986), we argue that both forms of knowledge may appear in virtual communities (Fueller and Matzler, 2007). For example, members might tell 
stories about their consumption experiences (Muniz and O'Guinn, 2001) but also provide facts about product failures (von Hippel, 2005). The digital setting of the VLUC limits the transfer of unwritten cues and contextual information, which are important for understanding use experiences and interpreting analogies. In turn, it favors the speedy transfer of concise and unambiguous knowledge that requires little additional explanation, that is, explicit knowledge (Roberts, 2000). Therefore, we hypothesize:

H4 (:). The knowledge value of contributions differs across their levels of codification. Explicit contributions provide greater value than do tacit contributions.

\section{Methodology}

This research focuses on the development of mobile, high-tech services, a field in which users frequently participate in innovation processes through VLUCs. Our research design adopts a combination of Netnography (Kozinets, 2002) and Consensual Agreement Technique (CAT, Amabile, 1983). Netnography uses publicly available posts in Internet fora to study the contribution behavior of community members; CAT uses subjective ratings by individuals or small groups to assess the novelty and relevance of information. Although Netnography represent a qualitative approach, by combining it with ratings of qualified coders, we can quantify the knowledge value of online contributions (e.g., Magnusson, 2009; Piller and Walcher, 2006). For example, Weiss et al. (2008) coded the contributions of marketing professionals to assess the value and impact of each contribution in a virtual community.

\subsection{Setting: Nokia BetaLabs}

As the empirical setting, we chose Nokia BetaLabs, a large virtual community in which technology-savvy lead users contribute to mobile service innovations. The community host Nokia is the world's largest mobile device manufacturer, with yearly worldwide sales of 400 million devices and a $40 \%$ market share (nokia.com). Recent pressures on its profit margins, the success of competitors such as Apple and BlackBerry in selling high-end mobile devices, and shifts in customer preferences toward more advanced services have led to a strategic reorientation at Nokia. Its focus has shifted from the development of products toward the development of new mobile services (Economist, 2008). As a platform that connects lead users of new mobile services with development teams, Nokia BetaLabs facilitates interactions and contributes to innovations; therefore, it plays a pivotal role in this development.

Furthermore, Nokia BetaLabs is an ideal setting for our study. First, mobile devices, as the platform for mobile services, are widely dispersed. Current estimates suggest that 4 billion are in use worldwide, which means that mobile device penetration exceeds those of previously introduced technologies, such as landline phones, computers, and televisions (www.itu.int). Mobile services also are expected to grow by $80 \%$ in the United States alone (Kleijnen et al., 2009). Second, Nokia BetaLabs was established in the beginning of 2007 and attracts a large amount of traffic (approximately 200,000 downloads and 1,000,000 page visits monthly). The maturity and size of this platform enable us to select complete and representative new service development projects for our study. Third, this community clearly establishes itself as a VLUC, as indicated in the 'About us' section of the Web site: "Nokia Beta Labs is a lead-user community." It holds typical VLUC features such as a future-orientation (community slogan: "We shape the future together") and an advanced status scheme (e.g., 'Active Contributor', 'Top Contributor', 'Bug Buster', 'Innovator', 'Top Reviewer') for which mainly the host determines the members' contribution behavior. Unlike some other communities, it does not serve other purposes, such as user support or product promotion, that attract more non-lead users. Unrelated requests, such as those about existing products or services, get forwarded to user support communities. Fourth, the profile of the members closely matches traditional lead user characteristics. For example, contributors to the 'Sportstracker' application are regular marathon runners who challenge this application with extreme usage situations. Also, community members show great product knowledge (e.g., referring to attributes of competitors' products) and innovativeness (e.g., experimenting with untested functions).

\subsection{Data collection}

We selected six finished projects dealing with mobile service innovations: Sportstracker (tracks and stores workouts), Gizmo (instant messaging and Internet calls), PC Suite (connects and synchronizes mobile devices with PCs), Loctagger (attaches GPS data images), Friends (location-blogging service to connect with friends), and Photos (transfers, organizes, geotags, and shares photos and videos). These applications are adequate for this investigation because they all deal with end consumers and thus eliminate the potential confounding effects of industrial users with different needs. Moreover, they generated the most traffic, in terms of downloads and contributions. Finally, the first and last contributions to the development of each application occurred between May and December 2008. Therefore, we can examine their entire development cycles and control for other effects, such as general market trends. We extracted all contributions in the discussion fora related to these projects (890). By eliminating spam or posts unrelated to the project, we attained 676 useable contributions.

\subsection{Measures}

We assessed the independent and dependent variables using CAT, which requires a panel of independent judges to evaluate the variables (Amabile, 1983). Prior to the evaluations, interviews with managers and developers of the hosting firm validated the operationalisation of the evaluation scheme and its applicability across the selected innovation projects. Because innovation work is typically conducted by project teams (Joshi and Sharma, 2004; Krishnan and Ulrich, 2001), we used teams of knowledgeable, specially trained raters to categorize the nominal variables and determine ratings for the ordinal variables. Two teams of 3-5 members each independently assessed the independent (focus, content, initiation, codification) and dependent (value: novelty, relevance) variables. Any conflicts in the assessments of the two groups were resolved through discussion. This procedure is similar to that adopted in prior studies pertaining to the development of new products and services when objective measures are not available (Piller and Walcher, 2006; Weiss et al., 2008). Subjective measures yield reliable and sound results that can account for the context dependence of the knowledge. To control for effects related to the project stage requirements and length of contributions, we included objective measures of the length and project stage as control variables. After the analysis, we validated our findings in meetings with managers and scholars in the field of innovation and refined the interpretation.

\subsubsection{Independent variables}

The focus of the contribution pertains to either a description of a mobile service's problem or a constructive development of a solution. The variable therefore is dichotomously coded as problem- or solution-focused. The type of content relates to the four exclusive dimensions of the mobile service's performance (reliability), design (aesthetics), usability (ergonomics), and functionality (Antioco et al., 2008; Krishnan and Ulrich, 2001). The initiation measure describes the contribution's level of proactivity. Specifically, it 
captures whether a contribution refers to the any preceding contribution in the discussion forum by classifying contributions as either responding or self-initiated. Finally, the level of codification is either explicit or implicit; the former relates to facts and figures, and the latter encompasses narrative descriptions of usage experiences.

\subsubsection{Dependent variables}

Before rating the value dimensions, we described the ratings, both orally and in writing, to the judging teams. The teams then assessed the contributions on a five-point scale (5: very high to 1: very low) in terms of their novelty (i.e., uniqueness and originality) and relevance (i.e., meaningfulness and appropriateness for the application). We averaged the responses on the two items and created a composite scale that represents the overall value of the contribution for the new service developments.

\subsubsection{Control variables}

Prior research suggests different knowledge needs emerge during the various stages of an innovation project (Zahay et al., 2011). For example, more novel knowledge is needed during earlier stages, but knowledge relevance is more important near the end of the project. To control for potential confounding effects, we split the contributions into three stages and coded each contribution according to its posting time. Furthermore, the length of a contribution might influence assessments, in that longer contributions likely contain more details and thus should receive higher relevance assessments. We classify each contribution according to the number of characters it contains, on a five-point scale.

\section{Findings}

\subsection{Assessment reliability}

The teams of judges simulated new product development teams. These judges possessed adequate knowledge of the field and received special training for the task. To reduce potential common method bias, we used each team twice and separated their assessments of the independent and dependent variables (Rindfleisch et al., 2008). We subsequently asked the teams about the difficulty of completing the task; they reported the tasks were at least 'neither easy nor difficult', which provides evidence of the satisfactory reliability of the assessment.

Regarding the nominal variables, the judging teams categorized focus (agreement: 84\%), initiation (88\%), and codification (61\%) into two categories and content (41\%) into four categories. Disagreements between the teams were resolved with the supervision of one of the authors. The teams rated ordinal variables on a five-point scale ranging from very high to very low. A Pearson bivariate correlation test showed significant $(p<.001)$ results for all the variables (novelty $r=.38$; relevance $r=.32$ ). These satisfactory correlations enable us to average the individual scores into mean scores for further analysis (Magnusson, 2009). Contributions equally comprise solutions (52\%) and problems (48\%), mainly relate to functionality (42\%) and performance (39\%) - and to a lesser extent to design (12\%) and usability (7\%) - are more self-initiated (76\%) than responding (24\%) and are slightly more explicit (57\%) than implicit (43\%). Knowledge novelty $(M=3.32, \mathrm{SD}=.87)$ and knowledge relevance $(M=3.44, \mathrm{SD}=.84)$ are similar in means and dispersion, show a significant high correlation (reliability $\alpha=.71$ ) and together constitute our dependent variable, knowledge value $(M=3.39, \mathrm{SD}=.74)$.

\subsection{Hypothesis testing}

We test our four knowledge value hypotheses with a one-way analysis of variance (ANCOVA). In parallel, we examine the individual effects for knowledge novelty and relevance using a MANCOVA in which we assess the robustness of the results across both dimensions. We control for the effects of length and project stage by including them as covariates. In addition, we test the differences between the groups using a t-test of mean scores; post-hoc tests cannot be used with covariates.

Our results show that the contributions' knowledge value $\left(F_{1,560}=11.16, p<.00\right)$ as well as novelty $\left(F_{1,560}=11.36, p<.00\right)$ and relevance $\left(F_{1,560}=4.86, p<.03\right)$ differ across the different types of focus. Solution-focused contributions are more valuable than problem-focused solutions, in support of $\mathrm{H}_{1}$. The contributions' impact also varies across different content types (overall value $F_{3,585}=4.82, p<.00$; novelty $F_{3,585}=4.65, p<.00$; relevance $\left.F_{3,585}=2.53, p<.06\right)$. When we compare the mean scores, we find significantly $(p<.05)$ higher values for functionality compared with performance and design but not compared with usability. In partial support of $\mathrm{H}_{2}$, we confirm that lead users' contributions generally are more valuable when they relate to functionality issues. The impact of initiation shows a (weak) effect on overall value $\left(F_{1,659}=3.02, p<.09\right)$ and novelty $\left(F_{1,659}=11.11, p<.00\right)$ but not on relevance $\left(F_{1,659}=.19, p=.67\right)$. Therefore, we can confirm $\mathrm{H}_{3}$ : Selfinitiated contributions to VLUCs are more valuable than responding contributions because the former provide more original insights. Finally, the results for $\mathrm{H}_{4}$ indicate a significant direct effect of the codification category on knowledge value $\left(F_{1,609}=3.95 ; p<.05\right.$; novelty $F_{1,609}=2.98, p<.09$; relevance $\left.F_{1,609}=2.65, p=.10\right)$. The higher knowledge value for explicit contributions suggests that the digital nature of VLUC favors the development of explicit knowledge (e.g., facts and figures) rather than implicit knowledge (e.g., narrative experience descriptions).

Table 1 summarizes the results of the analyzes (verb)/analyses (noun) of variance and the differences across group means.

\section{Discussion}

Virtual lead user communities seize technological opportunities to enable firms to access a diverse set of lead users in a cost-efficient

Table 1

Summary of results.

\begin{tabular}{|c|c|c|c|c|}
\hline \multirow[t]{2}{*}{ Hypothesis } & \multirow[t]{2}{*}{ Antecedents } & \multicolumn{3}{|l|}{ Outcomes } \\
\hline & & Value & Novelty & Relevance \\
\hline $\mathrm{H}_{1}$ & Focus & $\begin{array}{l}\text { +Solution } \\
\text {-Problem }\end{array}$ & $\begin{array}{l}\text { +Solution } \\
\text {-Problem }\end{array}$ & $\begin{array}{l}\text { +Solution } \\
\text {-Problem }\end{array}$ \\
\hline $\mathrm{H}_{2}$ & Content & $\begin{array}{l}\text { +Functionality } \\
\text {-Performance, design }\end{array}$ & $\begin{array}{l}\text { +Functionality } \\
\text {-Design, performance }\end{array}$ & $\begin{array}{l}\text { +Functionality } \\
\text {-Performance }\end{array}$ \\
\hline $\mathrm{H}_{3}$ & Initiation & $\begin{array}{l}\text { +Self-initiated } \\
\text {-Responding }\end{array}$ & $\begin{array}{l}\text { +Self-initiated } \\
\text {-Responding }\end{array}$ & n.s. \\
\hline $\mathrm{H}_{4}$ & Codification & $\begin{array}{l}\text { +Explicit } \\
\text {-Implicit }\end{array}$ & $\begin{array}{l}\text { +Explicit } \\
\text {-Implicit } \\
(p<.10)\end{array}$ & $\begin{array}{l}\text { +Explicit } \\
\text {-Implicit } \\
(p<.10)\end{array}$ \\
\hline
\end{tabular}

Notes: Significance level at .05 if not stated otherwise, n.s., not significant; +: high score, -: low score. 


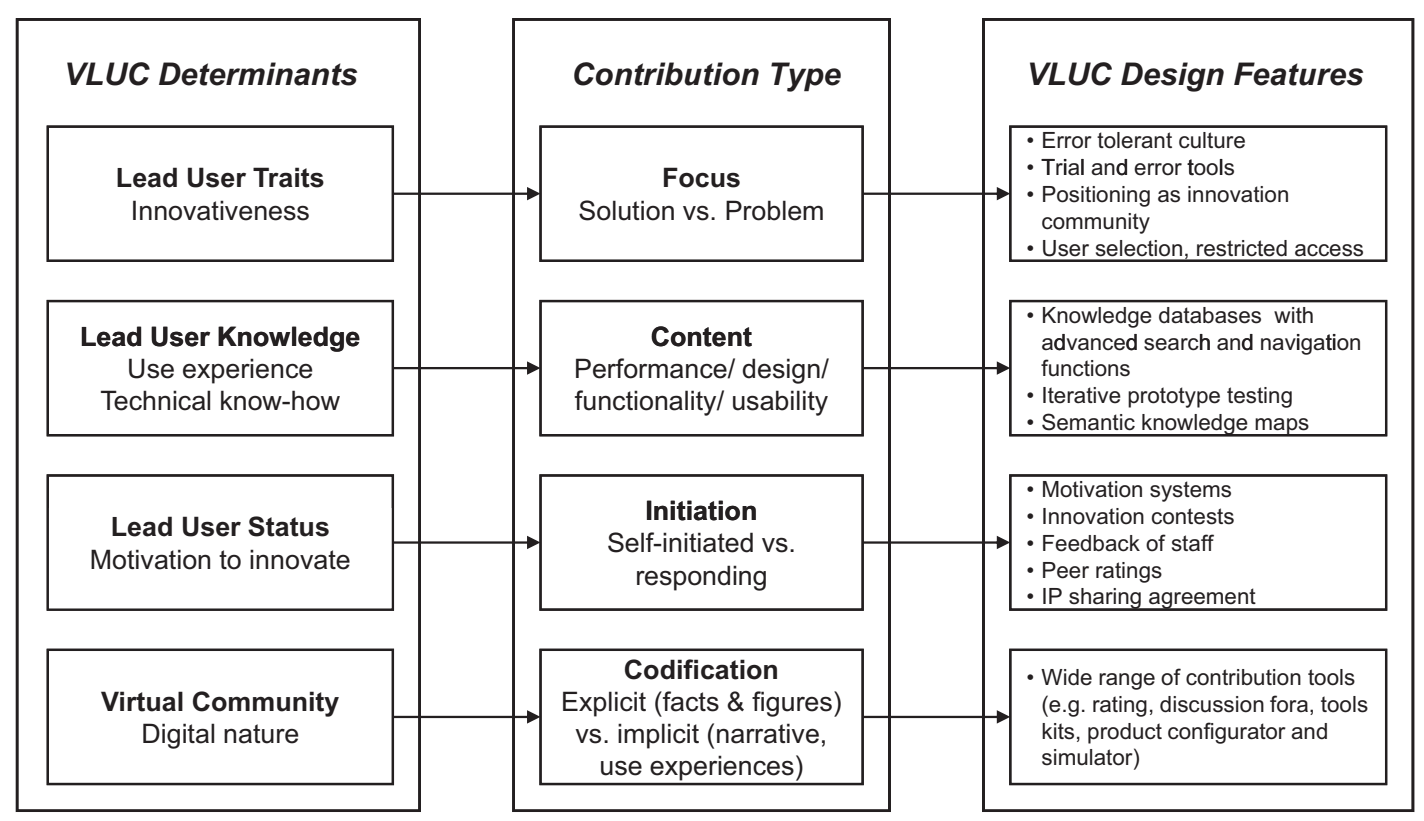

Fig. 1. Knowledge creation and exemplary VLUC design features.

way and co-create knowledge with them. This study defines VLUCs and reveals the type of knowledge that these communities create for a firm's innovation process. We relate well-established characteristics of lead users - being innovative, knowledgeable, and at the forefront of the market - and characteristics of virtual communities - information transfer mechanisms with limited physical and personal cues - to knowledge creation. Fig. 1 visualizes the conceptual relationships that we establish among VLUC determinants, types of lead user contributions, and exemplary VLUC design features.

The study's findings specifically suggest that the value of lead users in digital networks stems from their skills, not only in terms of describing needs and preferences but also for developing solutions to these needs. Lead users can articulate their contributions in a way that reduces misunderstanding and integrates easily with the firm's innovation process. However, these tech-savvy lead users are best suited for improvements pertaining to functionality rather than issues such as usability and aesthetic appearance.

\subsection{Design of VLUCS}

Our findings indicate that VLUCs may benefit from features that support their members' innovativeness. An error-tolerant and riskrewarding culture boosts the number and quality of new ideas. Members possess a shared dedication to innovation that distinguishes them from non-lead users. This shared consciousness is especially important in digital communities, because their boundaries are fuzzy, and access often cannot be controlled (Muniz and O'Guinn, 2001). Furthermore, VLUCs possess features that can enhance their members' knowledge. The innovating firm offers tools or databases that support individual knowledge updates. Lead users reflect on the extant knowledge in the community and collectively develop solutions through their iterative interactions with the host and other members (von Hippel, 2005).

Moreover, lead users at the forefront of the market expect significant benefits from innovations. Members freely reveal valuable information because they aim for product improvements in line with their needs, but also seemingly for irrational reasons. The VLUC hosts can enhance members' intrinsic motivations, such as overcoming mental challenges in problem solving, through organizing idea contests. Incentive systems should address users' feeling of ownership of the innovation, such as by acknowledging their contributions in product disclaimers, IP-sharing agreements, or status updates, which in turn should enhance users' future commitment and contributions (Sawhney and Prandelli, 2000). The provision of exclusive access to a new product - in our case, a new mobile application - may trigger members' sense of reciprocity (Harhoff et al., 2003). Awards instead stimulate extrinsic motivations, such as personal self-esteem, because they provide recognition as a successful innovator or problem solver. Therefore, VLUC incentive systems need to strike a balance between intrinsic and extrinsic motives. Later modifications are subject to more indepth scrutiny by members and may even prompt them to leave the community. Finally, VLUCs seize digital opportunities and contain features that can triangulate knowledge creation. Different interaction possibilities foster the transfer of tacit and explicit knowledge through small tasks, to which users contribute with seemingly limited cognitive and temporary effort (Hoffman and Novak, 1996). The sum of the various tools can trigger a positive online experience for members while also offering firms knowledge that they can incorporate into their innovation process (von Hippel, 1994).

\subsection{Knowledge created in VLUCS}

Previous research demonstrates that lead users' input may prompt more innovative and successful products. However, the involvement of lead users might not be beneficial in channels with limited transfer capacity (Daft and Lengel, 1986) or for all types of knowledge (Magnusson, 2009). Our findings shed light on these issues by revealing the impact of VLUCs on knowledge creation and thus lead to several major conclusions. Contributions provided by lead users possess the greatest value when they suggest solutions instead of simply describing problems or stating customer requirements. Although innovation processes require both needand solution-related information, customers often cannot express their needs or understand a firm's capabilities to develop solutions. Our findings suggest that lead users possess both the mental abilities and the field-related expertise to assess firms' solution capabilities. However, their knowledge typically relates to technical expertise, so the firm benefits mainly from contributions related to new functions and less from contributions to other issues, 
such as performance or usability improvements. While our study is conducted in the high-tech industry, its results correspond with general research that differentiates technical from market-oriented employees. The technical expertise of the former leads them to propose technical solutions that might not match the demands of most ordinary users (Moenaert and Souder, 1990). Yet, for such users enhanced usability and attractive design might be more important than possessing another, perhaps rarely used functionality. This conceptualization partly explains the success of Apple's iPod and iPhone lines, which provide an enjoyable customer experience through intuitive navigation and strong aesthetical appeal, rather than wider functionalities, compared with competitors' products (Meyer and Schwager, 2007).

In terms of codification, tacit knowledge is typically considered more novel and valuable because it contains details about customers' latent needs and usage motives (von Hippel, 1994). Our findings suggest that in VLUCs, explicit solutions actually are more novel and relevant than solutions containing implicit usage experiences in specific and tacit knowledge in general. The transfer of the latter demands familiarity with the individual usage context and trust (Nonaka, 1994), which is typical of repeated, interpersonal encounters but not infrequent, computer-mediated interactions (Sproull and Kiesler, 1986). The limited transferability of knowledge fits better with explicit contributions that leave less room for misinterpretation. This benefit may be amplified by lead users' technical expertise that assists explaining solutions in a clear, unambiguous, and comprehensible way and ensures product development teams understand these solutions (Luethje, 2004).

Finally, the creation of valuable knowledge in VLUCs differs according to members' level of proactivity. Contributions unrelated to other contributions contain more original insights than do contributions that represent responses. In other words, VLUCs benefit from proactive as opposed to reactive behavior (Narver et al., 2004). This study centers on the identification of valuable single contributions. Yet contributions often emerge from a learning process, during which members get inspired by information from within and outside the community (Nambisan, 2002). Examining the process of idea formation across time is beyond the scope of this study but may provide an interesting direction for further research.

\subsection{Managerial implications}

The challenges of developing new products and services to meet fast changing customer needs and taking advantage of new technical opportunities remain critical for firms. This study demonstrates how virtual innovation communities can be established in dynamic markets, as well as how to identify and trigger the creation of valuable knowledge by cooperating with lead users. For firms, investments in VLUCs are most beneficial when many users have heterogeneous needs and want to address them with individual solutions. In addition, lead users must be willing to experiment with innovations and share their experiences. Finally, the new products should require various types of knowledge that can be created through digital channels and tools.

When these conditions are fulfilled, firms should carefully select their VLUC features. This study provides guidance regarding the typical characteristics of lead users and digital channels. Key features include establishing an innovation-oriented culture, encouraging knowledge sharing and enhancement tools, and designing incentive systems and IP arrangements. Because of the differences in their objectives, audiences, and designs, firms should clearly separate their VLUCs from other user communities to attract and keep valuable lead users.

Finally, after the firm establishes the VLUC, its managers should stimulate active and involved discussions. A major challenge for firms is to select, from among the vast number of contributions, those that offer the most valuable knowledge (Hoyer et al., 2010). Our findings suggest that lead users' value stems from their ability to describe needs ahead of the market and develop solutions. Users therefore should be encouraged to suggest solutions, perhaps through solution contests, stories about best solution practices, and adequate incentive systems. The VLUC managers might advise development teams to pay special attention to functionality solutions, which are likely to be the most valuable ones for their innovations. To seize on the novelty of self-initiated contributions, managers might carefully steer lead users by asking open questions. At the same time, questions about existing products should move to another community, to protect the lead user network. The use of simple words, clear sentence structures, and explicit details can increase understanding of and value in users' contributions. The rules of participation established by the firm therefore should list recommendations and examples of preferred kind of language. Finally, our findings point to lead users' limited abilities to contribute performance and usability suggestions, which may reflect the different need patterns of lead and ordinary users. Lead users as innovators and early adopters may be interested in solutions that appeal to their sense of curiosity and prove their status as an innovator; in contrast, ordinary users often prefer reliable, simple-to-use products and services with good price-to-quality ratios (Meyer and Schwager, 2007; Moore, 2002). Knowledge creation in the VLUC therefore should be complemented by other sources, such as internal reliability tests and pre-launch test with ordinary users, to find specific usability improvements.

\subsection{Limitations and suggestions for further research}

Our study contains several limitations that provide opportunities for ongoing research, especially considering the recency of our study phenomena. We focus on knowledge value as the outcome of knowledge creation (Im and Workman, 2004), rather than its process. As mentioned previously though, dynamics and interrelatedness across contributions could provide intriguing research directions as well. For example, studies might examine specific discussion threads and how an initial idea gets formed and reshaped by subsequent contributions by other community members. Because of our focus on individual contributions, we have not included several user-related variables, such as perceived self-efficacy, sense of empowerment, or socio-demographics, which could help explain the novelty or relevance of users' contributions (Hoyer et al., 2010). Similarly, variety in innovation projects, such as their complexity, underlying technology and industry environment, might affect lead users' abilities to contribute. Although we carefully selected projects that are comparable in their volume and target market, additional studies should employ a multilevel approach to account for possible heterogeneity in these factors.

Other important questions that might frame ongoing research in this area relate to the design features of VLUCs. Research on the relative importance of these design features, such as selfpresentation functions, innovation contests, and communication tools for innovation-related contributions, remains scant but could have interesting implications for scholars and managers.

\subsection{Conclusion}

Virtual lead user communities can stimulate the creation of novel knowledge relevant for specific innovation projects. The greatest knowledge value stems from lead user contributions that suggest solutions to their needs and contain explicit descriptions of new functions. Further research is needed to understand how firms balance their portfolio of knowledge sources, such as VLUCs and 
internal employees, to uncover all types of knowledge necessary during the innovation process.

\section{References}

Amabile, T.M., 1983. The social psychology of creativity: a componential conceptualization. Journal of Personality and Social Psychology 45, 357-376.

Amabile, T.M., Conti, R., Coon, H., Lazenby, J., Herron, M., 1996. Assessing the work environment for creativity. Academy of Management Journal 39, 1154-1184.

Antioco, M., Moenaert, R.K., Lindgreen, A., 2008. Reducing ongoing product design decision-making bias. Journal of Product Innovation Management 25, 528-545.

Arrow, K.J., 1962. The economic implications of learning by doing. The Review of Economic Studies 29, 155-173.

Atuahene-Gima, K., Slater, S.F., Olson, E.M., 2005. The contingent value of responsive and proactive market orientations for new product program performance. Journal of Product Innovation Management 22, 464-482.

Audia, P.G., Goncalo, J.A., 2007. Past success and creativity over time: a study of inventors in the hard disk drive industry. Management Science 53, 1-15.

Bagozzi, R.P., Dholakia, U.M., 2006. Open source software user communities: a study of participation in Linux user groups. Management Science 52, 1099-1115.

Bettman, J.R., Luce, M.F., Payne, J.W., 1998. Constructive consumer choice processes. Journal of Consumer Research 25, 187-217.

Carbonell, P., Rodriguez-Escudero, A.I., Pujari, D., 2009. Customer involvement in new service development: an examination of antecedents and outcomes. Journal of Product Innovation Management 26, 536-550.

Chesbrough, H., 2003. Open Innovation: The New Imperative for Creating and Profiting from Technology. Harvard Business School Press, Boston.

Christensen, C.M., Bower, J.L., 1996. Customer power, strategic investment, and the failure of leading firms. Strategic Management Journal 17, 197-218.

Cohen, W.M., Levinthal, D.A., 1990. Absorptive capacity: a new perspective on learning and innovation. Administrative Science Quarterly 35, 128-152.

Daft, R.L., Lengel, R.H., 1986. Organizational information requirements, media richness and structural design. Management Science 32, 554-571.

Davis, R.E., 1993. The role of market research in the development of new consumer products. Journal of Product Innovation Management 10, 309-317.

Dholakia, U.M., Blazevic, V., Wiertz, C., Algesheimer, R., 2009. Communal service delivery: how customers benefit from participation in firm-hosted virtual P3 communities. Journal of Service Research 12, 208-226.

Economist, 2008. Nokia - Ovi go again. The Economist Newspaper and The Economist Group.

Eisenhardt, K.M., Martin, J.A., 2000. Dynamic capabilities: what are they? Strategic Management Journal 21, 1105-1121.

Franke, N., Shah, S., 2003. How communities support innovative activities: an exploration of assistance and sharing among end-users. Research Policy 32, 157-178.

Fueller, J., Matzler, K., 2007. Virtual product experience and customer participation - a chance for customer-centred, really new products. Technovation 27 , 378-387.

Gruner, K.E., Homburg, C., 2000. Does customer interaction enhance new product success? Journal of Business Research 49, 1-14.

Hansen, M.T., 1999. The search-transfer problem: the role of weak ties in sharing knowledge across organization subunits. Administrative Science Quarterly 44, $82-111$.

Harhoff, D., Henkel, J., Von Hippel, E., 2003. Profiting from voluntary information spillovers: how users benefit by freely revealing their innovations. Research Policy 32, 1753-1769.

Henard, D.H., Szymanski, D.M., 2001. Why some new products are more successful than others. Journal of Marketing Research 38, 362-375.

Hoffman, D., Novak, T., 1996. Marketing in hypermedia computer-mediated environments: conceptual foundations. Journal of Marketing 60, 50-68.

Hoyer, W.D., Chandy, R.K., Dorotic, M., Krafft, M., Singh, S.S., 2010. Consumer cocreation in new product development. Journal of Service Research 13, 283-296.

IBM, 2008. Global CEO Study - Enterprise of the Future. IBM Global Business Services, Somers, NY.

Im, S., Bayus, B.L., Mason, C.H., 2003. An empirical study of innate consumer innovativeness, personal characteristics, and new-product adoption behavior. Journal of the Academy of Marketing Science 31, 61-73.

Im, S., Workman, J.J.P., 2004. Market orientation, creativity, and new product performance in high-technology firms. Journal of Marketing 68, 114-132.

Jaworski, B., Kohli, A.K., 1993. Market orientation: antecedents and consequences. Journal of Marketing 57, 53-70.

Joshi, A.W., Sharma, S., 2004. Customer knowledge development: antecedents and impact on new product performance. Journal of Marketing 68, 47-59.

Kleijnen, M., Lievens, A., de Ruyter, K., Wetzels, M., 2009. Knowledge creation through mobile social networks and its impact on intentions to use innovative mobile services. Journal of Service Research 12, 15-35.

Kozinets, R.V., 2002. The field behind the screen: using netnography for marketing research in online communities. Journal of Marketing Research 39, 61-72.

Krishnan, V., Ulrich, K.T., 2001. Product development decisions: a review of the literature. Management Science 47, 1-21.
Kristensson, P., Gustafsson, A., Archer, T., 2004. Harnessing the creative potential among users. Journal of Product Innovation Management 21, 4-14.

Kristensson, P., Matthing, J., Johansson, N., 2008. Key strategies for the successful involvement of customers in the co-creation of new technology-based services. International Journal of Service Industry Management 19, 474-491.

Lakhani, K., Wolf, R.G., 2003. Why hackers do what they do. MIT Sloan School of Management Working Paper 4425-03.

Lengnick-Hall, C.A., 1996. Customer contributions to quality: a different view of the customer-oriented firm. Academy of Management Review 21, 791-824.

Lilien, G.L., Morrison, P.D., Searls, K., Sonnack, M., von Hippel, E., 2002. Performance assessment of the lead user idea-generation process for new product development. Management Science 48, 1042-1059.

Luethje, C., 2004. Characteristics of innovating users in a consumer goods field: an empirical study of sport-related product consumers. Technovation 24,683-695.

Luethje, C., Herstatt, C., 2004. The lead user method: an outline of empirical findings and issues for future research. R\&D Management 34, 553-568.

Madhavan, R., Grover, R., 1998. From embedded knowledge to embodied knowledge: new product development as knowledge development. Journal of Marketing 62, 1-12.

Magnusson, P.R., 2009. Exploring the contributions of involving ordinary users in ideation of technology-based services. Journal of Product Innovation Management 26, 578-593.

March, J.G., 1991. Exploration and exploitation in organizational learning. Organization Science 2, 71-87.

Meyer, C., Schwager, A., 2007. Understanding customer experience. Harvard Business Review 85, 117-126.

Moenaert, R.K., Souder, W.E., 1990. An information transfer model for integrating marketing and R\&D personnel in new product development projects. Journal of Product Innovation Management 7, 91-107.

Moore, G.A., 2002. Crossing the Chasm. Harper Paperbacks, New York.

Morrison, P.D., Roberts, J.H., Midgley, D.F., 2004. The nature of lead users and measurement of leading edge status. Research Policy 33, 351-362.

Morrison, P.D., Roberts, J.H., von Hippel, E., 2000. Determinants of user innovation and innovation sharing in a local market. Management Science 46, 1513-1527.

Muniz, A.M., O'Guinn, T., 2001. Brand community. Journal of Consumer Research 27 $412-432$.

Nambisan, S., 2002. Designing virtual customer environments for new product development: toward a theory. Academy of Management Review 27, 392-413.

Nambisan, S., Baron, R.A., 2009. Virtual customer environments: testing a model of voluntary participation in value co-creation activities. Journal of Product Innovation Management 26, 388-406.

Narver, J.C., Slater, S.F., MacLachlan, D.L., 2004. Responsive and proactive market orientation and new-product success. Journal of Product Innovation Management $21,334-347$.

Nonaka, I., 1994. A dynamic theory of organizational knowledge creation. Organizational Science 5, 14-37.

Oldham, G.R., Cummings, A., 1996. Employee creativity: personal and contextual factors at work. Academy of Management Journal 39, 607-634.

Olson, E.L., Bakke, G., 2001. Implementing the lead user method in a high technology firm: a longitudinal study of intentions versus actions. Journal of Product Innovation Management 18, 388-395.

Ozer, M., 2009. The roles of product lead-users and product experts in new product evaluation. Research Policy 38, 1340-1349.

Piller, F., Walcher, D., 2006. Toolkits for idea competitions: a novel method to integrate users in new product development. R\&D Management 36, 307-318.

Polanyi, M., 1966. The tacit dimension. Anchor Books, New York, NY.

Prahalad, C.K., Ramaswamy, V., 2004. The Future of Competition: Co-creating Unique Value with Customers. Harvard Business School Press, Boston.

Rindfleisch, A., Malter, A.J., Ganesan, S., Moorman, C., 2008. Cross-sectional versus longitudinal survey research: concepts, findings, and guidelines. Journal of Marketing Research 45, 261-279.

Roberts, J., 2000. From know-how to show-how? Questioning the role of information and communication technologies in knowledge transfer. Technology Analysis \& Strategic Management 12, 429-443.

Rowley, J., Kupiec-Teahan, B., Leeming, E., 2007. Customer community and cocreation: a case study. Marketing Intelligence \& Planning 25, 136-146.

Sawhney, M., Prandelli, E., 2000. Communities of creation: managing distributed knowledge in turbulent markets. California Management Review 42, 24-54.

Schreier, M., Pruegl, R., 2008. Extending lead-user theory: antecedents and consequences of consumers' lead userness. Journal of Product Innovation Management 25, 331-346.

Senge, P., 1990. The fifth discipline: the art and practice of organizational learning. Random House, Milsons Point, NSW.

Shah, S.K., 2006. Motivation, governance, and the viability of hybrid forms in open source software development. Management Science 52, 1000-1014.

Sproull, L., Kiesler, S., 1986. Reducing social context cues: electronic mail in organizational communications. Management Science 32, 1492-1512.

Thomke, S., 2001. Enlightened experimentation. The new imperative for innovation. Harvard Business Review 79, 66-75.

van Aken, J.E., 2004. Management research based on the paradigm of the design sciences: the quest for field-tested and grounded technological rules. Journal of Management Studies 41, 219-246.

von Hippel, E., 1986. Lead users: a source of novel product concepts. Management science $32,791-805$

von Hippel, E., 1994. Sticky information" and the locus of problem solving: implications for innovation. Management Science 40, 429-439. 
von Hippel, E., 2005. Democratizing Innovation. The MIT Press, Cambridge.

von Hippel, E., 2007. Horizontal innovation networks - by and for users. Industrial and corporate change $16,293-315$

Weiss, A.M, Lurie, N.H., Macinnis, D.J., 2008. Listening to strangers: whose responses are valuable, how valuable are they, and why? Journal of Marketing Research $45,425-436$.
Zahay, D., Griffin, A., Fredericks, E., 2011. Information use in new product development: an initial exploratory empirical investigation in the chemical industry. Journal of Product Innovation Management 28, 485-502.

Zollo, M., Winter, S.G., 2002. Deliberate learning and the evolution of dynamic capabilities. Organization Science 13, 339-351. 